\title{
INTRASTROMAL CORNEAL KERARING SEGMENTS FOR KERATOCONUS
}

\section{Aly Mohamed Bayoumy, MD, Adel Abdel Razek Farag, MD, Medhat Mohamed Shawky, MD, Mohamed Nader Abdel Hamid, MSc. \\ Ophthalmology department of Zagazig University Hospital.}

ABSTRACT
AIM: To assess the outcome of intrastromal corneal ring segments (Kera ring) for keratoconus.
Study design: Retrospective noncomparative interventional case series.
Patients and Methods: Sixty keratoconus eyes of 48 patients that had intrastromal corneal ring segments
(Kera ring) implantation mechanically were reviewed. Uncorrected visual acuity (UCVA), best spectacle-
corrected visual acuity (BSCVA), central corneal curvature, corneal astigmatism, and complications were
analyzed.
Results: At a mean follow-up period of 6 months, the UCVA improved in $90 \%$ of eyes, was unchanged in
$10 \%$, and none worsened. The BSCVA improved in $94 \%$ of eyes, was unchanged in $6 \%$, and none
worsened. The mean spherical equivalent (SE) was reduced from $7.42 \pm 2.5$ diopters (D) to $3.06 \pm 2.33 \mathrm{D}$.
and the mean refractive astigmatism, from $4.52 \pm 1.61 \mathrm{D}$ to $2.61 \pm 1.69$ D. The mean central corneal
curvature was reduced from $51.45 \pm 3.04 \mathrm{D}$ to $47.37 \pm 2.58 \mathrm{D}$. Intracorneal ring segment decentration
occurred in 2 eyes ( $3.3 \%$ ), segment extrusion in 10 eyes $(16.7 \%$ ), bacterial keratitis in 1 eye $(1.7 \%)$ with
segment extrusion, and a disciform keratitis in 1 eye $(1.7 \%)$.
Conclusion: Implantation of Kera ring segments in patients with keratoconus was a safe, effective and
reversible procedure that led to stable results, on the short term of six months. Further clinical and
experimental studies with more patients and longer follow-up are needed.
Keywords: (keratoconus - Keraring)

\section{INTRODUCTION}

Teratoconus is a disorder characterized by 1 progressive corneal steepening, most typically inferior to the centre of the cornea, with eventual central and para-central corneal thinning, induced myopia and irregular astigmatism. The prevalence of keratoconus in the general population appears to be relatively high, although the definition of cases varies in different series. ${ }^{1}$

The clinical findings of Keratoconus include corneal steepening, stromal thinning, conical protrusion, cone displacement, deep stromal stress lines (Vogt's striae), prominent corneal nerves, ring of iron deposition at the base of the cone (Fleischer ring), sub-epithelial corneal scarring and acute hydrops in advanced cases. $^{2}$

Several methods have been developed and used to assess the corneal shape and help in Keratoconus diagnosis and follow up. these include Placido disc, Keratometry, Photokeratoscope, Computerized videokeratoscopy (corneal topography), slit-scanning topography (Orbscan) and Scheimpflug imaging (Pentacam). ${ }^{3}$

Non surgical treatment modalities are initially tried, that include spectacles for correction of astigmatism and myopia, soft lenses of toric design, rigid gas permeable lenses for more advanced cases; these include multicurve spherical-based lenses, aspheric lenses, and biaspheric lenses, and hybrid lenses, which has a rigid central portion and a soft peripheral skirt. For very advanced cases hard contact lenses are used. ${ }^{4}$

Current Surgical options include: Intra stromal corneal ring segments (Intacs, Ferrara, Kera and Myo rings), Ultraviolet-A/Riboflavin corneal cross-linking, Lenticular (lens) refractive surgery including Phakic IOL implantation, and refractive lens exchange with regular or toric intraocular lens implantation, corneal refractive surgeries usually in combination with crosslinking and corneal transplantation (or grafting) including penetrating keratoplasty and Lamellar keratoplasty. ${ }^{5}$

Corneal ring segments are used for correction of Keratoconus. They consist of two polymethyl methacrylate (PMMA) segments; when surgically placed circumferentially into the periphery of the corneal stroma, they flatten the central anterior corneal curvature by increasing the peripheral thickness of the cornea. The goal of corneal rings implantation is not to eliminate the corneal disease but to decrease the corneal abnormality associated with it, decrease the central corneal curvature, improve the visual acuity in affected patients to satisfactory level, and eliminate or at least delay the need for a corneal graft. ${ }^{6}$

\section{PATIENTS AND METHODS}

Surgery was performed in 60 eyes of 48 patients with keratoconus. Keratoconus was stage II or III by Amsler classification, with no central corneal opacity, a maximum keratometric reading $(\mathrm{K})$ less 
than 60 D., and a minimal corneal thickness of $450 \mu \mathrm{m}$ at the incision site. All patients had a complete eye examination including visual acuity testing, cycloplegic refraction, slit lamp and fundus examination, and corneal imaging using The Oculus Pentacam with Scheimpflug imaging.

Ring segments used (Kera ring) were made of acrylic Perspex CQ (Medi-phacos) with an internal diameter $4.4 \mathrm{~mm}$ and the external diameter $5.4 \mathrm{~mm}$ for $5.0-\mathrm{mm}$ optical zone, thickness from 150 to $350 \mu \mathrm{m}$, and arc length 160 degrees. The ring segments have a prism format; the flat posterior surface is implanted facing the corneal endothelium. Optical correction is achieved with central corneal flattening, which is directly proportional to the ring thickness. Ring segment were selected based on the nomogram provided by the manufacturer. The nomogram depends on the ectasia distribution relative to the cornea, and the patient's spherical equivalent.

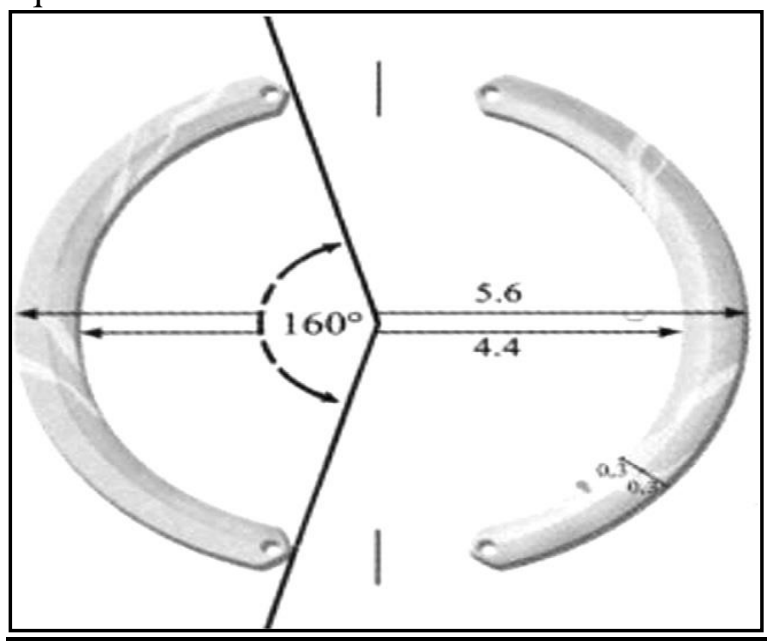

Fig. 1: Diagram showing the design and the diameter of Keraring.

\section{Surgical Technique}

Preoperative topical medication included tobramycin $0.3 \%$ eye drops every 60 minutes starting 2 hours before surgery. All surgeries were performed under general anesthesia.

The patient's eye globe was moved till the reflex of the coaxial microscope light coincided with the pupil center, then the central corneal reflex, the steepest corneal meridian and the optical zone were marked with an inner zone of $5.00 \mathrm{~mm}$ and an outer zone of $7.00 \mathrm{~mm}$ in diameter utilizing a $5 / 7 \mathrm{~mm} \mathrm{OZ}$ marker stained with a Gentian Violet marking pen. Intraoperative ultrasonic pachymetry was performed at the site of the incision, and the diamond knife was set at $80 \%$ of the calculated corneal thickness. $1.0 \mathrm{~mm}$ radial corneal incision, was made at the steep corneal meridian between optical zones using the diamond knife. Using Suarez spreader, to create two deep pocket on both sides of the incision. Then the Moreira Delaminators inserted into the stromal pockets slowly advanced between the $5 \mathrm{~mm}$ and 7 mm marks to create two deep stromal tunnels. The ring segments were implanted in the tunnels. Ketorolac drops were used every 15 minutes for 3 hours after surgery, and a combination of $0.1 \%$ dexamethasone and $0.3 \%$ tobramycin drops was used every 4 hours for 7 days, as well as methylcellulose $0.5 \%$ every 6 hours for 30 days. Patients were followed up at one day, one week, one month, three months, and six months postoperatively with visual acuity testing, cycloplegic refraction, slit lamp examination, and corneal imaging using The Oculus Pentacam with Scheimpflug imaging.

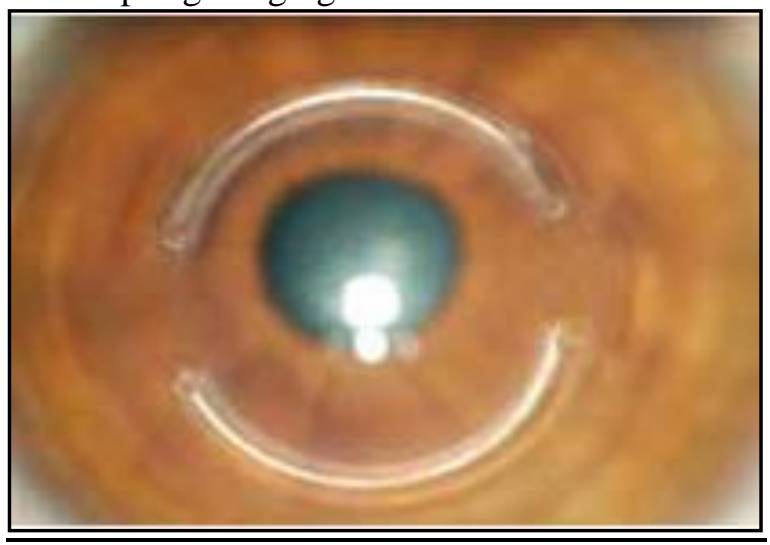

Fig. 2: Keraring implanted inside cornea Statistical Analysis

Data was analyzed using IBM SPSS Advanced Statistics version 20.0 (SPSS Inc., Chicago, IL). Numerical data were expressed as mean and standard deviation. Qualitative data were expressed as frequency and percentage. Chi-square test (Fisher's exact test) was used to examine the relation between qualitative variables. For quantitative data, comparison of repeated measures was done using ANOVA for repeated measures test. A p-value $<0.05$ was considered significant.

\section{RESULTS}

A total of 60 eyes of 48 patients diagnosed as keratoconus participated in this study; 29 males ( 9 bilateral) and 19 females (3 bilateral). All patients had intrastromal corneal ring segment (keraring) implantation. 


\begin{tabular}{|c|c|c|c|c|c|}
\hline & $\begin{array}{l}\mathrm{Me} \\
\text { an }\end{array}$ & $\begin{array}{l}\text { Standa } \\
\text { rd } \\
\text { Deviat } \\
\text { ion } \\
\end{array}$ & $\begin{array}{l}\text { Medi } \\
\text { an }\end{array}$ & $\begin{array}{l}\text { Minim } \\
\text { um }\end{array}$ & $\begin{array}{l}\text { Maxi } \\
\text { mum }\end{array}$ \\
\hline $\begin{array}{c}\text { Pre Seq } \\
\text { (D) }\end{array}$ & $\begin{array}{c}- \\
7.4 \\
2\end{array}$ & 2.50 & -7.00 & -14.00 & -2.00 \\
\hline $\begin{array}{c}\text { Pre } \\
\text { UCVA }\end{array}$ & $\begin{array}{c}0.0 \\
7 \\
\end{array}$ & 0.04 & 0.06 & 0.02 & 0.30 \\
\hline $\begin{array}{c}\text { Pre } \\
\text { BCVA }\end{array}$ & $\begin{array}{c}0.1 \\
9 \\
\end{array}$ & 0.11 & 0.20 & 0.06 & 0.50 \\
\hline Pre K1 & $\begin{array}{l}48 . \\
76 \\
\end{array}$ & 3.31 & $\begin{array}{c}49.0 \\
0 \\
\end{array}$ & 41.00 & 57.00 \\
\hline Pre K2 & $\begin{array}{r}54 . \\
14 \\
\end{array}$ & 3.08 & $\begin{array}{c}54.0 \\
0 \\
\end{array}$ & 45.50 & 60.00 \\
\hline $\begin{array}{c}\text { Pre K- } \\
\text { avg } \\
\end{array}$ & $\begin{array}{l}51 . \\
45 \\
\end{array}$ & 3.04 & $\begin{array}{c}51.5 \\
0 \\
\end{array}$ & 44.00 & 59.00 \\
\hline Pre cyl & $\begin{array}{c}4.5 \\
2 \\
\end{array}$ & 1.61 & 4.00 & 1.50 & 8.00 \\
\hline $\begin{array}{c}\text { Pre } \\
\text { Topogra } \\
\text { phic cyl }\end{array}$ & $\begin{array}{c}5.3 \\
9\end{array}$ & 1.99 & 5.00 & 1.50 & 11.00 \\
\hline
\end{tabular}

The mean preoperative central corneal curvature (average $\mathrm{K}$ ) was $51.45 \mathrm{D} \pm 3.04$ with $\mathrm{K} 148.76 \mathrm{D} \pm$ 3.31 and $\mathrm{K} 254.14 \mathrm{D} \pm 3.08$. That decreased postoperatively after 6 months to (average K) was $47.37 \mathrm{D} \pm 2.58$ with $\mathrm{K} 145.61 \mathrm{D} \pm 2.73$ and $\mathrm{K} 2$ $49.13 \mathrm{D} \pm 2.81$. The central corneal curvature decreased postoperatively after 6 months by a mean of $7.25 \%$.

\begin{tabular}{cccccc}
\hline & $\begin{array}{c}\text { Me } \\
\text { an }\end{array}$ & $\begin{array}{c}\text { Standa } \\
\text { Deviat } \\
\text { ion }\end{array}$ & $\begin{array}{c}\text { Medi } \\
\text { an }\end{array}$ & $\begin{array}{c}\text { Minim } \\
\text { um }\end{array}$ & $\begin{array}{c}\text { Maxi } \\
\text { mum }\end{array}$ \\
\hline Seq (D) & $\begin{array}{c}3.0 \\
6\end{array}$ & 2.33 & -3.00 & -10.00 & 2.00 \\
\hline ucva & $\begin{array}{c}0.2 \\
0\end{array}$ & 0.14 & 0.20 & 0.03 & 0.50 \\
\hline bcva & $\begin{array}{c}0.4 \\
0\end{array}$ & 0.16 & 0.40 & 0.10 & 0.80 \\
\hline K1 & $\begin{array}{c}45 . \\
61\end{array}$ & 2.73 & $\begin{array}{c}45.0 \\
0\end{array}$ & 40.00 & 52.00 \\
\hline K2 & $\begin{array}{c}49 . \\
13\end{array}$ & 2.81 & $\begin{array}{c}49.0 \\
0\end{array}$ & 44.00 & 55.00 \\
\hline K & $\begin{array}{c}47 . \\
37\end{array}$ & 2.58 & 47.0 & 42.50 & 53.50 \\
\hline cyl & $\begin{array}{c}2.6 \\
1\end{array}$ & 1.69 & 2.00 & 0.00 & 8.00 \\
\hline Topogra & 3.5 & 2.03 & 3.00 & 0.00 & 10.00 \\
\hline phic cyl & 2 & & & & \\
\hline
\end{tabular}

Table (2): Postoperative Data Analysis after 6 months.

Two eyes had ring segment decentration detected at the 3 months follow up. Best corrected Vision dropped from 0.2 to 0.08 and from 0.3 to 0.1 . Surgical centration of the segments was done under topical anaesthesia with a sinskey hook dissecting open the old incision and pushing the segment to its correct position easily and visual acuity subsequently returned to 0.2 and 0.3 respectively after 1 week.

Ten eyes had ring extrusion. All presented within 2 to 3 months postoperatively. Surgical removal of the segments was done under topical anaesthesia and visual acuity subsequently returned to the preoperative level.

One eye was diagnosed with Disciform keratitis after presenting at 5 months with severe haze adjacent to the segment; vision dropped from 0.5 uncorrected and best corrected to 0.3 uncorrected and 0.2 best corrected. The patient received 
treatment of topical prednisolone $1 \%$ every 2 hours for a week then gradual tapering over next 2 weeks. The corneal edema resolved, but visual acuity did not improve!

One eye at 1 month postoperatively had presumed bacterial keratitis; treated with intense topical Moxifloxacin (Vigamox) and ring removal as well as irrigation of the corneal tunnel with Moxifloxacin (Vigamox). The infection cleared after 15 days and visual acuity subsequently returned to the preoperative level.

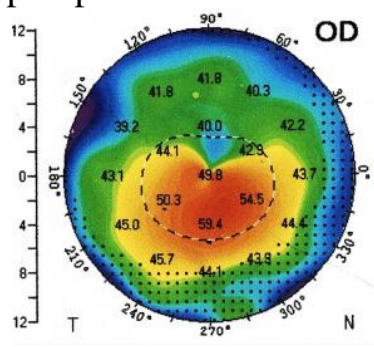

A: Preoperative
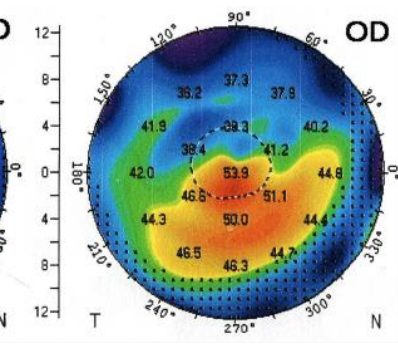

B: Postoperative
Fig. 3: The change in curvature map after Keraring implantation.

\section{DISCUSSION}

Intracorneal implantation of a synthetic material to correct spherical and cylindrical refractive errors is not a new idea; the placement of ICRS produce central corneal flattening effect, these segments act as spacer elements between the bundles of corneal lamellae, producing a shortening of the central arc length (arc-shortening effect). As a consequence of this effect, the central portion of the anterior corneal surface tends to flatten, and the peripheral area adjacent to the ring insertion is displaced forward. The ring segment diameter is proportionally inversed to this flattening intensity. Thus, the more the ring thickness, the higher is the myopic correction. ${ }^{7}$

Every segment has a double effect a flattening effect along the virtual line (axis) connecting the two ends of the segment, and a steepening effect perpendicular to that line. ${ }^{8}$

The Keraring and Ferrara ring segments, are triangular in shape implanted on $5 \mathrm{~mm}$ in diameter in respect to center of the pupil. The triangular anterior shape and flat posterior shape of the ring segments have a stronger effect on central corneal flattening; besides adding tissue to the corneal midperiphery, the tips of the ICRS lift anteriorly after implantation, adding an extra flattening effect in the meridian opposite implantation. The Prismatic effect, created by the triangular shape of the ring intending to eliminate the halo phenomena and obfuscation, that would be expected due to the reduced diameter. ${ }^{9}$

This surgery has the advantages of preserving the central cornea and of being a reversible procedure with a return to preoperative corneal and refractive parameters after ring removal in most cases. In addition, there is excellent corneal tolerance to PMMA rings with only short-term, low-grade inflammatory stromal reaction consisting of a discrete concentration of inflammatory cells adjacent to the rings. ${ }^{10}$

Ferrara was one of the first authors to suggest implantation of PMMA ring segments to correct keratoconus and irregular astigmatism. In the initial study, he reported using Ferrara ICRS to correct high myopia (up to $20.00 \mathrm{D}$ ), myopic and compound regular astigmatism, and irregular astigmatism due to keratoconus and PKP. He reported a significant reduction in spherical equivalent (from $10.20 \pm 5.98 \mathrm{D}$ to $2.02 \pm 2.02 \mathrm{D}$ ) and cylinder (from $4.09 \pm 2.42 \mathrm{D}$ to $1.89 \pm 1.31 \mathrm{D}$ ) after surgery with preservation of corneal asphericity and improvement in contrast sensitivity, BSCVA, and the topography pattern. ${ }^{11}$

In the present study also, a significant reduction in spherical equivalent was obtained by a mean of $(58.64 \%)$ and cylinder by a mean of $(40.41 \%)$. These results go along with those of the large multicenter study of 146 eyes of Pinero et al. ${ }^{12}$ where they had a mean decrease of spherical equivalent by $(55.56 \%)$ from $-5.58 \pm 3.85$ preoperatively to $-2.48 \pm 2.74$ postoperatively, and they reported a reduction in refractive astigmatism from $-4.33 \pm 2.33 \mathrm{D}$ preoperatively to $-2.56 \pm$ $1.76 \mathrm{D}$ postoperatively by a mean of $(40.88 \%)$.

In our series of keratoconus patients, the BCVA improved by 1-2 lines in 31 eyes (62\%) and more than 2 lines in 16 eyes $(32 \%)$ for a total improvement in 47 eyes (94\%). It did not change in 3 eyes $(6 \%)$, and none worsened $(0 \%)$. With Efficacy index ( 1.05 ) and Safety index ( 2.1 ). Efekan et al. ${ }^{13}$ reported improvement in BCVA in $(78 \%)$ of eyes with gain of one to four lines, $(18 \%)$ maintained the preimplantation BCVA, and $(4 \%)$ had decrease of up to two lines; but despite this deterioration in BCVA, the patients did not want to remove the ICRSs, because there was an increase of the UCVA.

The most frequent postoperative complication encountered in this study was ring extrusion in 10 eyes $(16.7 \%)$, this is probably related to either blunt trauma or eye rubbing (denied by the patients) or 
shallow dissection of corneal tunnels less than $75 \%$ of available stromal thickness. Kwitko and Severo 14 also had ring segment extrusion in $(19.6 \%)$ of cases, and Kanellopoulos et al. ${ }^{15}$ in 6 eyes (30\%).

One advantage of this surgery is that it is reversible if the ring has to be removed, and the segments can be reimplanted in a deeper tunnel in most cases 30 days or more after ring extrusion. Furthermore, if the achieved result is not as expected, the originally implanted ring can be exchanged for a thicker one to obtain a stronger effect.

Only 1 eye had a ring-related complication, disciform keratitis; this likely represented an immunologic reaction to the foreign body. The patient had no history of herpetic keratitis or any other form of herpes.

In the present study only 1 case diagnosed of presumed bacterial keratitis that resolved after ring explantation and vigorous topical and intracorneal antibiotic treatment. The BSCVA returned to the preoperative level.

\section{CONCLUSION}

In conclusion, Intrastromal corneal ring segments (Keraring) implantation is a viable alternative for patients with keratoconus offering a safe and effective therapeutic treatment providing good visual outcomes. Intrastromal corneal ring segments have the advantages of being potentially reversible, adjustable, and reasonably safe; it is an inexpensive procedure that avoids or at least delays penetrating keratoplasty in keratoconus patients. Further clinical and experimental studies with more patients and longer follow-up are needed to improve the safety and predictability and ensure the stability of results.

\section{REFERENCES}

1) Kaya , Karakaya , Utine et al. Evaluation of the corneal topographic characteristics of keratoconus with orbscan II in patients with and without atopy. Cornea 2007 Sep; 26(8). PP:945948.

2) Sugar . Stromal corneal dystrophies and ectasias. Yanoff ophthalmology, 1st edition. Mosby international Ltd 1999;(5). PP:1-10.

3) Lim, Wei , Chan, et al. Evaluation of keratoconus in Asians: role of Orbscan II and Tomey TMS-2 corneal topography. Am J Ophthalmol. 2007;143. PP:399-400.

4) Rosenthal and Cotter . Clinical performance of a splinebased apical vaulting keratoconus corneal contact lens design. CLAO J 1995;21. PP:42-46.

5) O'Brart and Robert : Keratoconus-Part 2 Surgical interventions. Optician 2006 (Nov); 232. PP:28-32.

6) Ertan and Colin : Intracorneal rings for keratoconus and keratectasia. J. Cataract. Refract. Surg. 2007;33. PP:1303-1314.

7) Pinero , Alio , Teus, et al.: Modeling the Intracorneal Ring Segment Effect in Keratoconus Using Refractive, Keratometric, and Corneal Aberrometric Data. IOVS 2010 Nov; 51(11). PP:5583-5591.

8) Akaishi, Tzelikis , and Raber : Ferrara intracorneal ring implantation and cataract surgery for the correction of pellucid marginal corneal degeneration. J Cataract Refract Surg 2004;30(11). PP:2427-2430.

9) Ferrara, Cunha , Cruz , et al.: Corneal ectasia and Ferrara ring. In: Intracorneal ring segments and alternative treatments for corneal ectatic diseases. Colin J, Ertan A (Eds). Kudret Göz Yayinlari, Ankara, Turkey 2007.

10) Barbara : Textbook on Keratoconus: New Insights 2012. 1st edition, Published by Jaypee Brothers Medical Publishers Ltd. Chapter 16 (Ferrara ring). PP:163-164.

11) Abu-Ameerh, Hamad, Ababneh, et al.: Ferrara ring segments implantation for treating keratoconus. Int J Ophthalmol. 2012;5(5). PP:586-590.

12) Pinero , Alio , El Kady, et al.: Refractive and aberrometric outcomes of intracorneal ring segments for keratoconus: mechanical versus femtosecond-assisted procedures. Ophthalmology 2009;116(9.) PP:1675-1687.

13) Coskunseven , Kymionisnik , Tsiklis , et al.: One-year results of intrastromal corneal ring segment implantation (Keraring) using femtosecond laser in patients with keratoconus. Am J Ophthalmol 2008;145(5). PP:775-779.

14) Kwitko and Severo : Ferrara intracorneal ring segments for keratoconus. J Cataract Refract Surg. 2004 Apr;30(4). PP:812-820.

15) Kanellopoulos , Pe , Perry , et al.: Modified intracorneal ring segment implantations (INTACS) for the management of moderate to advanced keratoconus: efficacy and complications. Cornea 2006 Jan;25(1). PP:2933. 